REVISTA ANDALUZA DE ANTROPOLOGÍA.

NÚMERO 3: MIGRACIONES EN LA GLOBALIZACIÓN.

SEPTIEMBRE DE 2012

ISSN 2174-6796

[pp. 242-246]

http://dx.doi.org/10.12795/RAA.2012.i03.13

\title{
HERNÁNDEZ RAMÍREZ, Javier (2011) Tiempo de hornadas. Etnografía de la actividad calera en Santa Ana la Real. Huelva: Diputación de Huelva, 174 pp.
}

\author{
Esther Fernández de Paz
}

Universidad de Sevilla

Tiempo de hornadas. Etnografía de la actividad calera en Santa Ana la Real es una monografía que el profesor Javier Hernández Ramírez aporta al conocimiento y puesta en valor de una parte del patrimonio cultural andaluz. Una contribución en la que cabría destacar, en primer lugar, su cercanía: son los caleros del pueblo onubense de Santa Ana la Real, sus familias y sus gentes todas, los protagonistas de este libro y es a ellos a quienes va prioritariamente dirigido. De ahí que el autor presentara los resultados de su publicación 'in situ', a pie de los hornos de cal restaurados, rodeado de la atención de los santaneros. Es un estudio, por tanto, ofrecido en primer lugar a los sujetos de la investigación.

No podía ser de otro modo teniendo en cuenta que, tras muchos años de olvido y abandono, la iniciativa de rehabilitación de los hornos de cal y de la recuperación de la memoria del oficio de calero partió de un grupo local, la Asociación Cultural Valle de Santa Ana. Conscientes del valor patrimonial de estos bienes, los integrantes de esta agrupación fueron sensibilizando a sus convecinos de la necesidad de salvaguardar esa parte de su historia colectiva. Así arrancó, en 1999, un proceso de patrimonialización, todavía hoy inconcluso. 
Nos hallamos, consiguientemente, ante un nuevo ejemplo de activación patrimonial de abajo hacia arriba, tan frecuente hoy día como insólito poco tiempo atrás. En la actualidad puede constatarse cómo una gran parte de la sociedad conoce, estima y defiende el legado cultural que conforma su patrimonio, y no sólo grandiosas e históricas construcciones sino también los elementos más sencillos y cotidianos, además del propio entorno natural. Una actitud que de manera inevitable desemboca en que, en no pocas ocasiones, sea ella quien solicite y hasta reclame insistentemente a la administración competente la adopción de las medidas oportunas para su protección.

El cambio de mentalidad, o mejor, la ampliación de la consideración patrimonial que esto supone, no ha sido fácil de alcanzar. Cuando se trata de elementos que, si no están todavía vigentes, han dejado de estarlo recientemente, no se puede volcar en ellos el sentimiento de lo histórico, esa categoría capaz de ennoblecer y, por tanto, reconvertir en referentes patrimoniales lo que hasta ese momento se veía simplemente como algo viejo y en desuso. Máxime si esos elementos provienen de un duro mundo laboral que pretende desterrarse. Esta respuesta, por lo demás comprensible, puede llegar a dificultar la percepción que se tiene sobre el patrimonio etnológico, modesto y cotidiano, frente al patrimonio docto y monumental que refleja precisamente sublimados patrones de suntuosidad.

El trabajo de la cal en Santa Ana la Real puede testimoniar este proceso de modificación paulatina de significados. Lo que en principio sólo era un medio de vida, poco valorado incluso por los propios caleros, cae de lleno en el olvido tras su obligado abandono, hasta que la labor de revalorización de un grupo de vecinos comienza a dar fruto. Es entonces cuando aquellos hornos que nacieron como instalaciones productivas y se trocaron después en construcciones desmanteladas, pasan a ser elementos dignos de estima y protección, símbolos de identificación colectiva que enlazan culturalmente el pasado y el presente de la población.

Javier Hernández precisa cómo la iniciativa popular consiguió que el Ayuntamiento de Santa Ana la Real se entusiasmara con el proyecto y comprara y restaurara tres hornos de los varios que sobrevivían ruinosamente en la ladera del Cerro Castillejo. El camino para su salvaguarda estaba abierto, culminándose, a escala municipal, con la inclusión de los hornos como bienes patrimoniales en el Plan General de Ordenación Urbana. De esta forma se recogió en la redacción de 2004, definitivamente aprobada dos años después. Desde ese momento son calificados como bienes inmuebles de valor etnológico ligados a actividades productivas tradicionales.

El paso siguiente para la protección patrimonial, el prescriptivo informe para su inclusión en el Catálogo General del Patrimonio Histórico Andaluz, es justamente el que lleva al profesor Hernández hasta los hornos de cal. Y al encargo de la Consejería de Cultura de la Junta de Andalucía se sumó el de la Delegación Provincial de Cultura de Huelva para la propuesta de medidas conducentes a la puesta en valor de esta parte del patrimonio santanero. 
A todo ello ha dado sobrada respuesta el investigador y las ha volcado en esta publicación. Además de narrar todo el proceso de activación de estos elementos patrimoniales, teorizándolo en base al carácter construido de todo patrimonio, el texto recoge un inventario de los hornos supervivientes, junto a una detallada documentación del oficio, de sus saberes y su vocabulario, útiles y herramientas, y el enunciado de proyectos de actuación.

Aunque su desarrollo es anterior, el oficio no aparece documentado hasta 1899. Para este desfase, el autor apunta como principal razón la circunstancia de tratarse de una actividad complementaria destinada al autoconsumo y a un reducido mercado, antes de alcanzar la especialización productiva, consecuencia de la diversificación de las bases económicas. Es entonces cuando se convierte en una labor distintiva de Santa Ana la Real, que particulariza a este municipio dentro del contexto serrano en el que se inserta.

El trabajo empieza a decaer en la década de los sesenta del pasado siglo, ante la imposibilidad de estos hornos artesanales de competir con la producción industrial de cemento. Unos hornos -personalizados con un nombre propio que aún mantienen- que, tras cada cierre, van quedando como únicos testigos del oficio perdido. Unos hornos que durante su vida activa fueron cambiando de ubicación en una constante búsqueda de optimización productiva, dictada por la situación de las canteras de caliza, el emplazamiento del combustible e incluso la modificación de los sistemas de transporte. En cualquier caso, el emplazamiento final de estas construcciones jamás fue arbitrario; muy por el contrario, responde a una lógica de aprovechamiento del desnivel del terreno, que supone en sí misma el primer testimonio del acervo de conocimientos precisos para el desarrollo de cualquier oficio tradicional.

Por ello, tan obligado es salvar estas edificaciones de su destrucción, como irrenunciable es la recopilación de los conocimientos. Sin la transmisión de los saberes tradicionales de los caleros que le dieron vida, sólo se conseguiría la permanencia de unos inmuebles singulares, desprovistos de memoria cultural, que en breve plazo no serían más que vacías estructuras decorativas.

Cuando además, como en este caso, los únicos poseedores de dichos conocimientos son artesanos de avanzada edad, incluso la legislación patrimonial recoge el deber ineludible de documentación. Desde la Ley 16/1985, de Patrimonio Histórico Español: “Cuando se trate de conocimientos o actividades que se hallen en previsible peligro de desaparecer, la Administración competente adoptará las medidas oportunas conducentes al estudio y documentación científicos de estos bienes" ( $\operatorname{art}^{\circ}$ 47.3), hasta la Ley 14/2007, de Patrimonio Histórico Andaluz: “Asimismo serán especialmente protegidos aquellos conocimientos o actividades que estén en peligro de desaparición, auspiciando su estudio y difusión, como parte integrante de la identidad andaluza. A tal fin se promoverá su investigación y la recogida de los mismos en soportes materiales que garanticen su transmisión a las futuras generaciones" ( $\operatorname{art}^{\circ}$ 63). Sin olvidar las recomendaciones internacionales al respecto, especialmente referidas a las promulgadas por la UNESCO, entre las que sobresale, por la novedad que supuso, la Convención para la 
Salvaguarda del Patrimonio Cultural Inmaterial, dada en el año 2003. En ella recomienda: "fomentar estudios cientificos, técnicos y artísticos, así como metodologías de investigación, para la salvaguardia eficaz del patrimonio cultural inmaterial, y en particular del patrimonio cultural inmaterial que se encuentre en peligro" ( $\left.\operatorname{art}^{\circ} 13 . c\right)$.

Tampoco renuncia el profesor Javier Hernández a hacer una llamada a los 'Tesoros Humanos Vivos', una figura de protección, también adoptada por la UNESCO, aunque ideada desde hace más de medio siglo en Japón. Como su nombre indica, el celo protector no recae entonces en los objetos sino directamente en la persona capaz de crearlos. Desde su nombramiento como tal, la única misión de un tesoro vivo será reproducir y enseñar la riqueza de sus conocimientos con la finalidad de asegurar la transmisión a las futuras generaciones. Hoy son ya muchos los países que han puesto en práctica este modo efectivo de traspasar un saber hacer que esté considerado valioso para la identidad cultural de un colectivo. No es el caso de España.

Ahondando en aspectos legislativos, Javier Hernández no se limita a relatar la situación en la que se encuentran las caleras de Santa Ana la Real sino que analiza las actuaciones de las distintas administraciones, destacando lo positivo y razonando lo negativo.

Sorprende así constatar cómo la Consejería de Medio Ambiente de la Junta de Andalucía obvia por completo el valor patrimonial de los hornos en todos sus planes del Parque Natural de Aracena y Picos de Aroche, donde se hallan enclavados. En cuanto a la protección que al fin encontraron en el Plan General de Ordenación Urbana, queda bien especificada la prohibición de modificar sus estructuras y fisonomías, pero el mismo PGOU no permite ningún tipo de actividad que altere el medio, incluyendo la extractiva, con lo que cierra toda posibilidad de hacer uso de las canteras y volver a poner en funcionamiento alguno de los hornos. Y ésta es justamente una de las propuestas de actuación que el profesor Hernández apunta en su publicación, entendiendo que con la recuperación de la producción de cal a pequeña escala, no sólo se mantendrían vivos las instalaciones y los conocimientos sino que se aportaría un producto de calidad, siquiera sea para su utilización en la restauración y preservación del patrimonio arquitectónico tradicional serrano.

Otra de las iniciativas que enuncia es la creación de un Centro de Interpretación que ayude a la comprensión del trabajo de la cal como bien cultural que caracteriza al territorio. Un acercamiento debido a los lugareños y ofrecido a los visitantes, para un mejor entendimiento del patrimonio calero. La difusión de sus valores se completaría con el proyecto de 'La Ruta de la Cal', concebida como un itinerario por las propias instalaciones.

Con ello el investigador se está adentrando en la resemantización del patrimonio. Adecuadamente incluidos en políticas de desarrollo endógeno, los hornos de cal de Santa Ana la Real pueden ofrecer una nueva rentabilidad, dirigida ahora hacia el turismo. Indiscutiblemente, para el Parque Natural es hoy uno de los sectores de más peso, y añadir una oferta diferenciada incrementaría sin duda su potencial. 
Así se ha entendido también en otro importante centro calero andaluz, como es Morón de la Frontera, en la provincia de Sevilla. Durante siglos ha sido la principal actividad económica del lugar, acompañada de la más alta significación simbólica. Aún hoy, la cal de Morón, sinónimo de calidad y pureza, constituye uno de los principales referentes identitarios de esta ciudad. Aquejada asimismo por la competencia industrial, fue también una iniciativa ciudadana, encauzada por la Asociación Cultural Hornos de Cal de Morón, quien crea y gestiona un centro de interpretación y un museo inserto en antiguos hornos restaurados, donde se muestra el procedimiento de fabricación artesanal. Sus numerosas actuaciones en pro de la difusión del oficio, incluida una Ruta de la Cal, le han valido el reciente reconocimiento de la UNESCO, dentro de la Lista del Patrimonio Cultural Inmaterial, en el apartado de 'Programas, proyectos y actividades para la salvaguardia del patrimonio que reflejen del modo más adecuado los principios y objetivos de la Convención'.

Dos años antes, en 2009, la Consejería de Cultura había procedido a la inscripción en el Catálogo General del Patrimonio Histórico Andaluz (CGPHA) de estas Caleras de la Sierra, como Bien de Interés Cultural, con la tipología de Lugar de Interés Etnológico. En estos momentos cabe esperar que no se demore más en la incoación del expediente administrativo que desemboque en la inscripción de los hornos de Santa Ana la Real en dicho CGPHA. Un trámite para el que la documentación aportada en esta publicación resulta de incalculable valor.

En resumen, Javier Hernández nos ofrece una obra realizada a la par con escrupulosa rigurosidad y con contagioso entusiasmo. A pesar de estar dedicada a un oficio perdido, es una obra que rezuma vida. Intachable metodológicamente, en cada capítulo explica las técnicas utilizadas y las fuentes consultadas, además de dejar que los mismos caleros regalen al lector sus recuerdos, expresándolos con sus propias palabras. En reconocimiento, aunque no en la forma habitual de dedicatoria, sí se puede leer en sus páginas la intención del investigador: "El presente trabajo es un homenaje a estos hombres que con su trabajo construyeron la arquitectura de la sierra y la historia de su pueblo". 